\title{
Expression of cell adhesion molecules in canine choroid plexus tumors
}

\author{
Naoki HIROSE ${ }^{1)}$, Kazuyuki UCHIDA ${ }^{1) *}$, Satoru MATSUNAGA ${ }^{2)}$, James Kenn CHAMBERS $^{1)}$ and Hiroyuki NAKAYAMA ${ }^{1)}$ \\ 1) Department of Veterinary Pathology, Graduate School of Agricultural and Life Sciences, the University of Tokyo, Tokyo 113-8657, Japan \\ 2) Japan Animal Referral Medical Center, 2-5-8 Kuji, Takatsu-ku, Kawasaki-shi, Kanagawa 213-0032, Japan
}

(Received 24 July 2014/Accepted 10 October 2014/Published online in J-STAGE 6 November 2014)

ABSTRACT. Choroid plexus tumor (CPT) is a primary intracranial neoplasm of the choroid plexus epithelium in the central nervous system. In the current World Health Organization classification, CPT is classified into two categories; choroid plexus papilloma (CPP) and carcinoma (CPC). In the present study, we investigated immunohistochemical expressions of $\mathrm{N}$-cadherin, E-cadherin and $\beta$-catenin in 5 canine CPT cases ( 1 disseminated CPC, 2 CPCs and 2 CPPs). One CPP case was positive for N-cadherin and $\beta$-catenin, but negative for E-cadherin. The disseminated $\mathrm{CPC}$ case was positive for E-cadherin and $\beta$-catenin, but negative for $\mathrm{N}$-cadherin. The other cases were positive for the three molecules examined. These results suggest that loss of the N-cadherin expression might associate with the spreading of CPC cells. KEY WORDS: $\beta$-catenin, cadherin, canine, choroid plexus tumor, immunohistochemistry

doi: 10.1292/jvms.14-0381; J. Vet. Med. Sci. 77(2): 255-259, 2015

Choroid plexus tumor (CPT) is a primary intracranial neoplasm derived from the choroid plexus epithelium in the central nervous system (CNS) and account for approximately 9\% of canine intracranial CNS tumors [10]. Since CPTs in dogs were first reported in 1936 [16], many cases have been reported $[2-5,9,12-15,18-20,22-24,26-29,31,32,34$, 35]. Middle-aged dogs are predominantly affected with CPT, and the fourth ventricle is the most common place of origin [31]. According to the current World Health Organization (WHO) classification, CPT is classified into 2 categories: benign choroid plexus papilloma (CPP) and malignant choroid plexus carcinoma (CPC) [11].

Neural cadherin (N-cadherin), epithelial cadherin (E-cadherin) and $\beta$-catenin are cell adhesion molecules. $\mathrm{N}$-cadherin is expressed mainly in the neurons, lens, striated muscle and cardiac muscle, while E-cadherin in many epithelial tissues $[6,33]$. $\beta$-catenin is an intracellular binding partner of Ecadherin $[17,21]$. E-cadherin and $\beta$-catenin could, therefore, be markers for less differentiated carcinoma. The decrease of E-cadherin expression was observed in malignant canine colorectal tumors [25], and the high expression of Ecadherin down-regulated the tumor cell invasion [30]. The decreased expression of $\beta$-catenin on the cell membrane and the alternative increase of its expression in the cytoplasm were observed in less differentiated carcinomas [25].

The present paper describes pathological and immunohistochemical features of a disseminated CPC, and the decrease of cell adhesion molecules could be related to the metastasis or dissemination of neoplastic cells.

*Correspondence to: Uchida, K., Department of Veterinary Pathology, Graduate School of Agricultural and Life Sciences, the University of Tokyo, Tokyo 113-8657, Japan.

e-mail: auchidak@mail.ecc.u-tokyo.ac.jp

(C2015 The Japanese Society of Veterinary Science

This is an open-access article distributed under the terms of the Creative Commons Attribution Non-Commercial No Derivatives (by-nc-nd) License $<$ http://creativecommons.org/licenses/by-nc-nd/3.0/>.
Among the 5 CPT cases, 2 dogs were male, and 3 were female. Median age of the cases was 7 years (range: 3-12 years). Primary site of tumor was not identified in 1 case, while they arose in the fourth ventricle in 3 cases and in the lateral ventricle in 1 case. Tumor tissues from 4 cases (case nos. 1, 2, 4 and 5) were collected during necropsy, while case no. 3 was obtained as a biopsy sample by a surgical resection. All the cases were diagnosed at the Department of Veterinary Pathology, Graduate School of Agricultural and Life Sciences, the University of Tokyo. Clinical features of the dogs are summarized in Table 1.

Case histories of the dogs were as follows. Case no. 1 showed the stumbling in rear limbs and 5 months later the opisthotonus and incomplete paralysis in forelimbs. The postural reflex in the both right limbs was lost, the patellar reflex in the right rear limb was enhanced, the menace response in the right eye was lost, the direct pupillary light reflex in the both eyes was weakened, the indirect pupillary light reflex in the both eyes was lost, and cervical muscles in both sides were atrophied. The results of magnetic resonance image (MRI) examination of case no. 1 revealed multiple lesions measuring 2 to $13 \mathrm{~mm}$ in diameter in the right ventral thalamus, right temporal lobes, right and left occipital lobes and left pons (Fig. 1A-C). Signal intensity of these lesions was low in the T1-weighted image, while high in the T2weighted image. The intensity of the lesions was suppressed in the FLAIR image. These findings indicated that these lesions were cystic masses. No significant dilation of any ventricles was observed. The primary site of the tumor in the case was not clearly determined, because several cystic or massive lesions were found in the ventricles. Since the patient had a convulsion when she was awake, the owner wanted euthanasia. Necropsy was done in the same day. Case no. 2 had the head tilt, was unable to walk and lacked the postural reflexes in all the limbs. After natural death, necropsy was done. Case no. 3 had the left side head tilt, and his stumbling got worse. Since the MRI examination revealed a mass lesion between the right cerebellar hemisphere 
Table 1. Clinical features of the 5 dogs with choroid plexus tumor

\begin{tabular}{|c|c|c|c|c|c|}
\hline $\begin{array}{l}\text { Case } \\
\text { no. }\end{array}$ & Breed & Gender & $\begin{array}{l}\text { Age } \\
\text { (years) }\end{array}$ & $\begin{array}{l}\text { Primary site of tumor } \\
\text { (ventricle) }\end{array}$ & Clinical symptoms \\
\hline 1 & Labrador retriever & $\mathrm{F}$ & 9 & Not identified & $\begin{array}{l}\text { Stumbling in rear limbs, opisthotonus, incomplete paralysis in forelilmbs, } \\
\text { loss of postural reflex in right limbs, enhance of right patellar reflex, loss of } \\
\text { right menace response, decline in both direct pupillary light reflex, loss of } \\
\text { both indirect pupillary light reflex, atrophy of cervical muscles }\end{array}$ \\
\hline 2 & French bulldog & $\mathrm{F}$ & 3 & 4th & Head tilt, unable to walk, lack of postural reflex \\
\hline 3 & Mix & M & 12 & 4 th & Left side head tilt, stumbling \\
\hline 4 & $\begin{array}{l}\text { Flat-coated } \\
\text { retriever }\end{array}$ & M & 5 & Lateral & Lethargy, anorexia, aggression, right side head turn \\
\hline 5 & Toy poodle & $\mathrm{F}$ & 7 & 4th & Left side head tilt, ataxia \\
\hline
\end{tabular}

Table 2. Histopathological findings of the 5 dogs with choroid plexus tumor

\begin{tabular}{ccccccccc}
\hline $\begin{array}{c}\text { Case } \\
\text { no. }\end{array}$ & $\begin{array}{c}\text { Loss of papillary } \\
\text { formation }\end{array}$ & Epithelial layering & Necrosis & Local invasion & Mineralization & Mitoses & $\begin{array}{c}\text { Nuclear } \\
\text { atypia }\end{array}$ & Diagnosis \\
\hline 1 & Partially found & Partially found & Not evident & Obvious & + & Rare & Low & Disseminated CPC \\
2 & Partially found & Partially found & Not evident & Not found & + & Rare & Low & CPP \\
3 & Not found & Not found & Not evident & Not determined & - & Occasional & Low & CPP \\
4 & Partially found & Partially found & Not evident & Obvious & + & Occasional & Severe & CPC \\
5 & Partially found & Partially found & Not evident & Obvious & - & Rare & Severe & CPC \\
\hline
\end{tabular}

$\mathrm{CPC}$, choroid plexus carcinoma; CPP, choroid plexus papilloma.

and medulla oblongata, biopsy was conducted. Case no. 4 presented the lethargy, anorexia, aggression and right side head turn. MRI examination revealed a mass lesion in the right ventricle. The patient was euthanized with the owner's consent, and necropsy was done. Case no. 5 presented the left side head tilt and ataxia. Computed tomography (CT) examination revealed a mass lesion at the right side of the cerebellum. After natural death, necropsy was conducted.

All tumor tissues were fixed in 10\% neutral bufferedformalin and embedded in paraffin. Paraffin sections were cut at $4 \mu \mathrm{m}$ and stained with hematoxylin and eosin (HE). Histological diagnoses were done based on the WHO classification [11]. Criteria for the tumor grading were as follows: CPP was not invasive and the tumor cells had a scant nuclear atypia and a low frequency of mitoses, while CPC was invasive and the tumor cells had a nuclear atypia and/or metastases. That is, all invasive CPTs were diagnosed as CPC, regardless of mitoses or nuclear atypia. We then performed immunohistochemistry using primary antibodies including mouse monoclonal antibodies to N-cadherin (1:25, DakoJapan, Kyoto, Japan) and to E-cadherin (1:100, Invitrogen, Camarillo, CA, U.S.A.), and rabbit antiserum to $\beta$-catenin (1:400, Millipore, Billerica, MA, U.S.A.). Deparaffinized sections were autoclaved at $121^{\circ} \mathrm{C}$ for $10 \mathrm{~min}$ in the Target Retrieval solution (pH 9.0, Dako-Japan). The sections were incubated at $4^{\circ} \mathrm{C}$ overnight with each primary antibody. Then, the sections were incubated with the EnVision+System-HRP labeled polymer (Dako-Japan). The reaction products were visualized with $0.05 \% 3-3^{\prime}$-diaminobenzidine and $0.03 \%$ hydrogen peroxide, and the sections were counterstained with hematoxylin. The normal choroid plexus from a necropsied dog was used as a control. To clarify the expression
Table 3. Immunoreactivity of CPT cells

\begin{tabular}{llc}
\hline \multicolumn{1}{c}{ Case } & & \% Immunopositive cells \\
\hline Normal CP & $\beta$-catenin & 100.0 \\
& E-cadherin & 61.9 \\
& N-cadherin & 100.0 \\
Case no. 1 (dCPC) & $\beta$-catenin & 99.2 \\
& E-cadherin & 32.9 \\
& N-cadherin & 0.0 \\
Case no. 2 (CPP) & $\beta$-catenin & 89.9 \\
& E-cadherin & 59.6 \\
Case no. 3 (CPP) & N-cadherin & 72.3 \\
& $\beta$-catenin & 77.0 \\
& E-cadherin & 0.0 \\
Case no. 4 (CPC) & N-cadherin & 56.9 \\
& $\beta$-catenin & 33.1 \\
& E-cadherin & 39.1 \\
Case no. 5 (CPC) & N-cadherin & 32.2 \\
& $\beta$-catenin & 44.4 \\
& E-cadherin & 22.5 \\
& N-cadherin & 68.1 \\
\hline
\end{tabular}

$\mathrm{CP}$, choroid plexus; $\mathrm{dCPC}$, disseminated $\mathrm{CPC}$.

level of each adhesion molecule, the number of cells positive for $\mathrm{N}$-cadherin, E-cadherin or $\beta$-catenin was counted in 10 different microscopic fields under $\mathrm{x} 400$ magnification. Then, the ratio of the positive cells was calculated.

Histopathological features of the 5 dogs with CPT are summarized in Table 2. Particularly, case no. 1 was diagnosed as disseminated CPC based on the local invasion to the third ventricle and a wide-dissemination throughout the cerebrum, cerebellum and brain stem (Figs. 2 and 3). How- 
ever, mitotic figures in the neoplastic cells were rare, nuclear atypia was low, loss of papillary formation was partially observed, and necrosis was not evident (Fig. 4). In case no. 2, diagnosed as CPP, while loss of papillary formation and epithelial layering were partially observed, both necrosis and local invasion were not evident. Mitotic figures were rare, and nuclear atypia was low. In case no. 3, diagnosed as CPP, local brain invasion was not observed at least on the biopsy section. In case no. 4, diagnosed as CPC, while loss of papillary formation and epithelial layering were partially found, necrosis was not evident. However, local invasion of the neoplastic cells was obvious, mitotic figures were occasional, and nuclear atypia was severe. In case no. 5 , diagnosed as CPC, while loss of papillary formation and epithelial layering were partially found and necrosis was not evident, local invasion of the neoplastic cells was obvious. Mitotic figures were rare, but nuclear atypia was severe. Mineralization in the neoplastic lesion (psammoma body) was observed in case nos. 1, 2 and 4 .

The results of immunohistochemistry are summarized in Table 3. Interestingly, in the case with a wide leptomeningeal dissemination (case no. 1), the tumor cells were immunopositive for E-cadherin (Fig. 5) and $\beta$-catenin (Fig. 6), whereas negative for N-cadherin (Fig. 7). On the contrary, in case no. 3 diagnosed as CPP, the tumor cells were negative for Ecadherin. In the other cases (case nos. 2, 4 and 5), the tumor cells were positive for all the three molecules examined.

According to Westworth et al. [31], 35\% of CPC cases showed an apparent subarachnoid metastasis. The previous observation is consistent with the result of the present study, in which 1 of 3 CPC cases showed metastasis along the neuroaxis. There have been some reports $[31,35]$ indicating that the fourth ventricle was the most common original location of CPT, while another report [26] indicated that $75 \%$ of CPTs occurred in the supratentorial region. Among the present 5 CPTs, 3 (case nos. 2, 3 and 5) arose in the fourth ventricle, 1 (case no. 4) in the lateral ventricle, and the remaining one (case no. 1) was thought to arise in the third ventricle.

We also examined the expressions of vimentin, cytokeratin AE1/AE3 and glial fibrillary acidic protein (GFAP) in case no. 1 (data not shown). The results were almost the same as those in the previous reports $[2,7,23,26]$. A small number of neoplastic cells were focally positive for GFAP in a previous report [7], while there were no positive cells in the lesion of the present case no.1.

According to Nentwig et al. [19], the expression levels of E-cadherin and $\beta$-catenin were higher in CPTs than that in normal choroid plexus. This is inconsistent with the present report, where the expression of E-cadherin and $\beta$-catenin decreased in CPTs compared to normal choroid plexus (Table 3 ). In the present study, case no. 3 did not show the expression of E-cadherin. This indicates that loss of its expression could occur sporadically in CPTs; however, since the significant decrease or loss of the E-cadherin expression in single benign and malignant CPTs was also observed in the previous study [19], the loss of the E-cadherin expression might not be causative in metastasis of CPTs. As Nentwig et al. mentioned in the previous report [19], there may be mechanisms other than the loss of E-cadherin expression conferring invasive and metastatic properties to CPTs. Therefore, we focused on $\mathrm{N}$-cadherin expression (discussed below).

Moreover, the expression levels of $\beta$-catenin tend to be fewer in CPC (case nos. 4 and 5) than CPP (case nos. 2 and 3 ), i.e., loss of $\beta$-catenin expression was observed with increasing malignancy, inconsistent with the previous report [19], where there was no relation in the $\beta$-catenin expression with the malignancy of CPTs.

Although the previous report [19] focused on the expression of E-cadherin and $\beta$-catenin in CPTs, there have been so far no reports on that of $\mathrm{N}$-cadherin. In the present study, we clarified the lack of the $\mathrm{N}$-cadherin expression in the disseminated CPC case (case no. 1). These results indicate that the dissemination and invasion of canine CPC could be related to the lack of the $\mathrm{N}$-cadherin expression. The decrease in the E-cadherin expression and the increase in the $\beta$-catenin expression in the cytoplasm, which had been reported in malignant cases [25], were not found in the present cases. That is, there was no difference in the expression patterns between CPTs and normal choroid plexus. Moreover, there is no apparent relationship between the E-cadherin and $\mathrm{N}$ cadherin expressions in the present study. On the other hand, a previous report indicated that the expression of $\mathrm{N}$-cadherin showed a negative relationship with that of E-cadherin in the feline mammary tumor cells [1]. The negative correlation between E-cadherin and N-cadherin expressions was also reported in another study [8], in which the invasion of canine meningioma into the nervous parenchyma was related to the expression of $\mathrm{N}$-cadherin. These discrepancies lead us to a hypothesis that the $\mathrm{N}$-cadherin expression may play a different role in CPTs and other tumors, respectively, because $\mathrm{N}$-cadherin was not expressed in the normal epithelial cells including mammary gland epithelia and meninges, while it was expressed in the normal choroid plexus. In other words, roles of $\mathrm{N}$-cadherin in CPTs may be different from its roles in other tumors. A decrease in the expression of $\mathrm{N}$-cadherin could cause metastasis or dissemination of CPT cells.

Accumulation of CPT cases and further investigations are needed to clarify the involvement of $\mathrm{N}$-cadherin in the meningeal dissemination of CPC cells and to confirm the relation between the expression levels of the cell adhesion molecules and the dissemination of canine CPC.

\section{REFERENCES}

1. Buendia, A. J., Peñafiel-Verdu, C., Navarro, J. A., Vilafranca, M. and Sanchez, J. 2013. N-cadherin expression in feline mammary tumors is associated with a reduced E-cadherin expression and the presence of regional metastasis. Vet. Pathol. 51: 755-758 [Epub ahead of print]. [Medline] [CrossRef]

2. Cantile, C., Campani, D., Menicagli, M. and Arispici, M. 2002. Pathological and immunohistochemical studies of choroid plexus carcinoma of the dog. J. Comp. Pathol. 126: 183-193. [Medline] [CrossRef]

3. Chénier, M., Gosselin, Y., Teuscher, E. and Breton, L. 1983. Paradoxic vestibular syndrome associated with choroid plexus papilloma in a dog. J. Am. Vet. Med. Assoc. 182: 66-67. [Medline]

4. Cotchin, E. 1953. Primary carcinoma of the choroid plexus of 


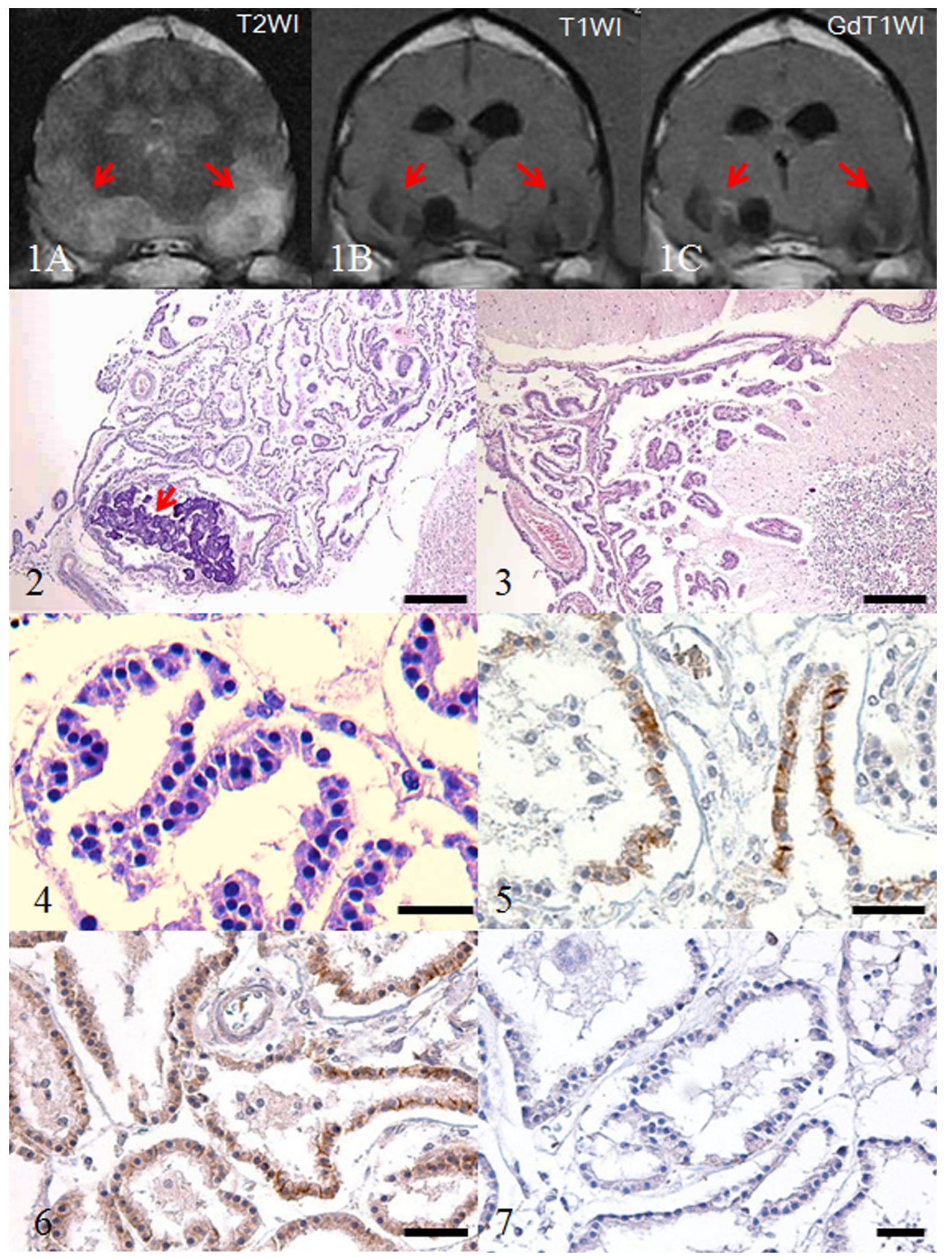


the fourth ventricle in a dog. J. Pathol. Bacteriol. 65: 257-258. [Medline] [CrossRef]

5. Hammer, A., Couto, C., Getzy, D. and Hunter, W. 1990. Magnetic resonance imaging in a dog with a choroid plexus carcinoma. $J$. Small Anim. Pract. 31: 341-344. [CrossRef]

6. Hatta, K., Okada, T. S. and Takeichi, M. 1985. A monoclonal antibody disrupting calcium-dependent cell-cell adhesion of brain tissues: possible role of its target antigen in animal pattern formation. Proc. Natl. Acad. Sci. U.S.A. 82: 2789-2793. [Medline] [CrossRef]

7. Ide, T., Uchida, K., Kikuta, F., Suzuki, K. and Nakayama, H. 2010. Immunohistochemical characterization of canine neuroepithelial tumors. Vet. Pathol. 47: 741-750. [Medline] [CrossRef]

8. Ide, T., Uchida, K., Suzuki, K., Kagawa, Y. and Nakayama, H. 2011. Expression of cell adhesion molecules and doublecortin in canine anaplastic meningiomas. Vet. Pathol. 48: 292-301. [Medline] [CrossRef]

9. Indrieri, R., Holliday, T., Selcer, R., Ackerman, N. and Taylor, J. 1980. Choroid plexus papilloma associated with prolonged signs of vestibular dysfunction in a young dog. J. Am. Anim. Hosp. Assoc. 16: 263-268.

10. Koestner, A. and Higgins, R. 2002. Tumors of the nervous system. pp. 709-712. In: Tumors in Domestic Animals, 4th ed. (Meuten, D. ed.), Iowa State Press, Iowa.

11. Koestner, A., Bilzer, T., Fatzer, R., Schulman, F., Summers, B. and Van Winkle, T.1999. Choroid plexus tumors. pp. 23-24. In: Histological Classification of Tumors of the Nervous System of Domestic Animals., Armed Forces Institute of Pathology, Washington, DC.

12. Kraft, S. L., Gavin, P. R., DeHaan, C., Moore, M., Wendling, L. R. and Leathers, C. W. 1997. Retrospective review of 50 canine intracranial tumors evaluated by magnetic resonance imaging. $J$. Vet. Intern. Med. 11: 218-225. [Medline] [CrossRef]

13. Kurtz, H. J. and Hanlon, G. F. 1971. Choroid plexus papilloma in a dog. Vet. Pathol. 8: 91-95. [Medline]

14. Lipsitz, D., Levitski, R. E. and Chauvet, A. E. 1999. Magnetic resonance imaging of a choroid plexus carcinoma and meningeal carcinomatosis in a dog. Vet. Radiol. Ultrasound 40: 246-250. [Medline] [CrossRef]

15. Loomis, L. and Keep, J. 1964. Choroid plexus papilloma in a dog. Br. Vet. J. 120: 336-339.

16. Milks, H. 1936. Primary brain tumors in small animals. Cornell Vet. 26: 159-170.

17. Nagafuchi, A. and Takeichi, M. 1989. Transmembrane control of cadherin-mediated cell adhesion: a $94 \mathrm{kDa}$ protein functionally associated with a specific region of the cytoplasmic domain of E-cadherin. Cell Regul. 1: 37-44. [Medline]

18. Nashold, B. S. Jr., Moore, G. T. Jr. and Gills, J. P. 1961. Papilloma of the choroid plexus in a Weimaraner dog. J. Neurosurg. 18: 250-251. [Medline] [CrossRef]

19. Nentwig, A., Higgins, R. J., Francey, T., Doherr, M., Zurbriggen, A. and Oevermann, A. 2012. Aberrant E-cadherin, $\beta$-catenin, and glial fibrillary acidic protein (GFAP) expression in canine choroid plexus tumors. J. Vet. Diagn. Invest. 24: 14-22. [Medline] [CrossRef]

20. Ohashi, F., Kotani, T., Onishi, T., Katamoto, H., Nakata, E. and
Fritz-Zieroth, B. 1993. Magnetic resonance imaging in a dog with choroid plexus carcinoma. J. Vet. Med. Sci. 55: 875-876. [Medline] [CrossRef]

21. Ozawa, M., Baribault, H. and Kemler, R. 1989. The cytoplasmic domain of the cell adhesion molecule uvomorulin associates with three independent proteins structurally related in different species. EMBO J. 8: 1711-1717. [Medline]

22. Palmer, A. C., Malinowski, W. and Barnett, K. C. 1974. Clinical signs including papilloedema associated with brain tumours in twenty-one dogs. J. Small Anim. Pract. 15: 359-386. [Medline] [CrossRef]

23. Pastorello, A., Constantino-Casas, F. and Archer, J. 2010. Choroid plexus carcinoma cells in the cerebrospinal fluid of a Staffordshire Bull Terrier. Vet. Clin. Pathol. 39: 505-510. [Medline] [CrossRef]

24. Patnaik, A. K., Erlandson, R. A., Lieberman, P. H., Fenner, W. R. and Prata, R. G. 1980. Choroid plexus carcinoma with meningeal carcinomatosis in a dog. Vet. Pathol. 17: 381-385. [Medline]

25. Restucci, B., Martano, M., DE Vico, G., Lo Muzio, L. and Maiolino, P. 2009. Expression of E-cadherin, $\beta$-catenin and APC protein in canine colorectal tumours. Anticancer Res. 29: 2919-2925. [Medline]

26. Ribas, J. L., Mena, H., Braund, K. G., Sesterhenn, I. A. and Toivio-Kinnucan, M. 1989. A histologic and immunocytochemical study of choroid plexus tumors of the dog. Vet. Pathol. 26: 55-64. [Medline] [CrossRef]

27. Snyder, J. M., Shofer, F. S., Van Winkle, T. J. and Massicotte, C. 2006. Canine intracranial primary neoplasia: 173 cases (1986-2003). J. Vet. Intern. Med. 20: 669-675. [Medline]

28. Thomas, W., Wheeler, S., Kramer, R. and Kornegay, J. 1996. Magnetic resonance imaging features of primary brain tumors in dogs. Vet. Radiol. Ultrasound 37: 20-27. [CrossRef]

29. Turrel, J. M., Fike, J. R., LeCouteur, R. A. and Higgins, R. J. 1986. Computed tomographic characteristics of primary brain tumors in 50 dogs. J. Am. Vet. Med. Assoc. 188: 851-856. [Medline]

30. Vleminckx, K., Vakaet, L. Jr., Mareel, M., Fiers, W. and van Roy, F. 1991. Genetic manipulation of E-cadherin expression by epithelial tumor cells reveals an invasion suppressor role. Cell 66: 107-119. [Medline] [CrossRef]

31. Westworth, D. R., Dickinson, P. J., Vernau, W., Johnson, E. G., Bollen, A. W., Kass, P. H., Sturges, B. K., Vernau, K. M., Lecouteur, R. A. and Higgins, R. J. 2008. Choroid plexus tumors in 56 dogs (1985-2007). J. Vet. Intern. Med. 22: 1157-1165. [Medline] [CrossRef]

32. Wilson, R. B., Holscher, M. A. and West, W. R. 1989. Choroid plexus carcinoma in a dog. J. Comp. Pathol. 100: 323-326. [Medline] [CrossRef]

33. Yoshida, C. and Takeichi, M. 1982. Teratocarcinoma cell adhesion: identification of a cell-surface protein involved in calcium-dependent cell aggregation. Cell 28: 217-224. [Medline] [CrossRef]

34. Zaki, F. A. and Kay, W. J. 1974. Carcinoma of the choroid plexus in a dog. J. Am. Vet. Med. Assoc. 164: 1195-1197. [Medline]

35. Zaki, F. A. and Nafe, L. A. 1980. Choroid plexus tumors in the dog. J. Am. Vet. Med. Assoc. 176: 328-330. [Medline]

Fig. 1. Magnetic resonance images. Case no. 1. A: T2WI, B: T1WI and C: T1WI contrasted with gadolinium. Multiple neoplastic lesions between the right and left temporal lobes (arrows).

Fig. 2. HE stain. Case no. 1. Papillary proliferation of tumor cells in the third ventricle. Psammoma body (arrow). Bar: $500 \mu \mathrm{m}$.

Fig. 3. HE stain. Case no. 1. Tumor cells proliferation in the cerebellar meninges and invasion into the parenchyma. Bar: $500 \mu \mathrm{m}$.

Fig. 4. HE stain. Case no. 1. Scant mitosis and mild nuclear atypia. Bar: $100 \mu \mathrm{m}$.

Fig. 5. Immunohistochemistry. Case no. 1. Expression of E-cadherin in the tumor cells. Bar: $100 \mu \mathrm{m}$.

Fig. 6. Immunohistochemistry. Case no. 1. Expression of $\beta$-catenin in the tumor cells. Bar: $100 \mu \mathrm{m}$.

Fig. 7. Immunohistochemistry. Case no. 1. No expression of N-cadherin in the tumor cells. Bar: $100 \mu \mathrm{m}$. 